University of Nebraska - Lincoln

DigitalCommons@University of Nebraska - Lincoln

8-2012

\title{
The Trade and Welfare Impacts of Australian Quarantine Policies: The Case of Pigmeat
}

John C. Beghin

Mark Melatos

Follow this and additional works at: https://digitalcommons.unl.edu/ageconfacpub

Part of the Agricultural Economics Commons, Economic Policy Commons, Food Microbiology Commons, and the Food Security Commons

This Article is brought to you for free and open access by the Agricultural Economics Department at DigitalCommons@University of Nebraska - Lincoln. It has been accepted for inclusion in Faculty Publications: Agricultural Economics by an authorized administrator of DigitalCommons@University of Nebraska - Lincoln. 


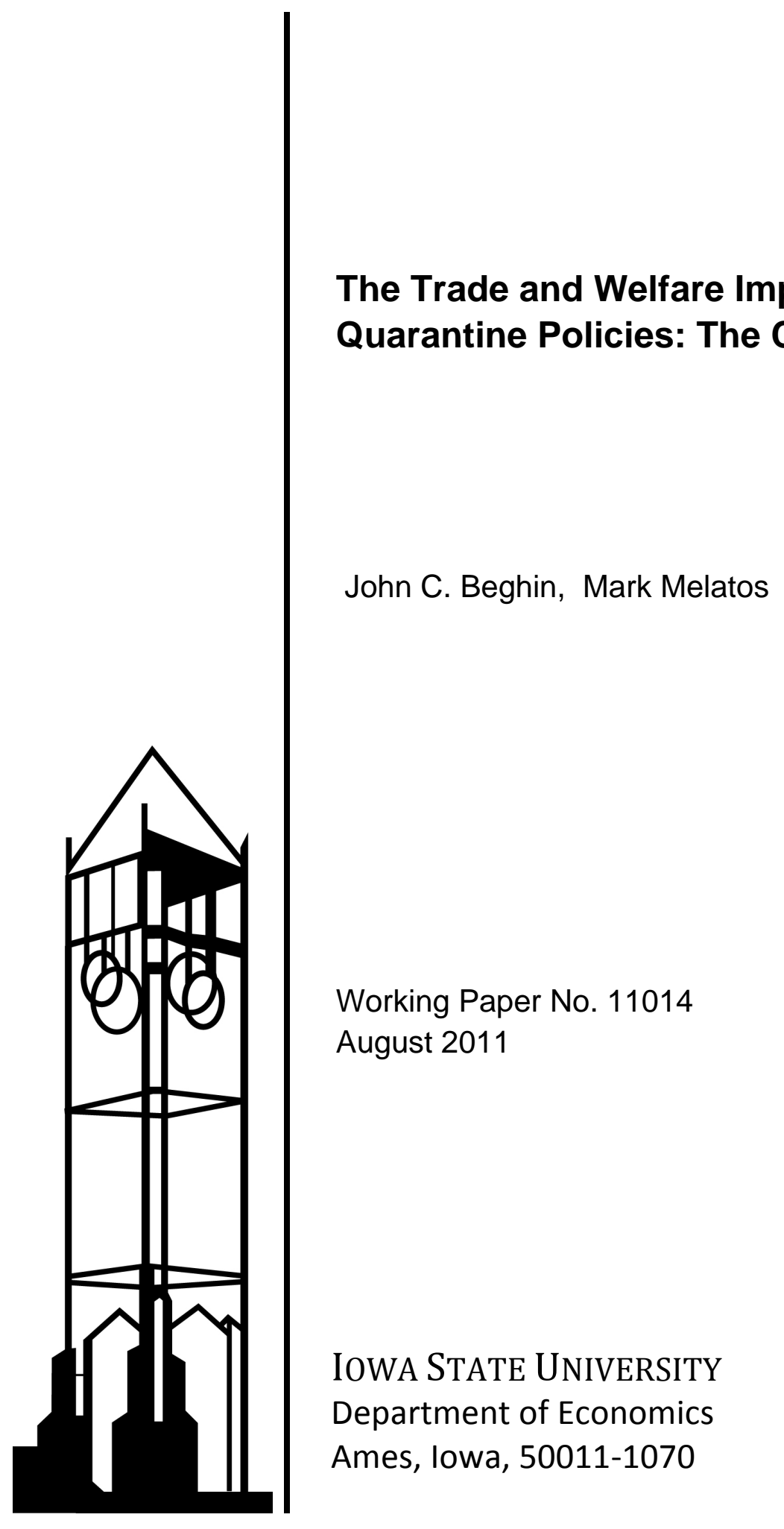

lowa State University does not discriminate on the basis of race, color, age, religion, national origin, sexual orientation, gender identity, genetic information, sex, marital status, disability, or status as a U.S. veteran. Inquiries can be directed to the Director of Equal Opportunity and Compliance, 3280 Beardshear Hall, (515) 294-7612. 


\title{
The Trade and Welfare Impact of Australian Quarantine Policies: The Case of Pigmeat
}

\author{
John Beghin (Iowa State University) \\ Mark Melatos (University of Sydney)*
}

\section{This draft: January 16, 2012}

\begin{abstract}
We analyze the trade and welfare impact of quarantine measures imposed by Australia on imports of pigmeat. In particular, we account for changes to Australia's pigmeat quarantine policy over time including those changes related to the recent resolution of a WTO dispute between Australia and the European Union. Using a random utility model, and applying it to corner solutions in import decisions, tariff equivalents (by major trading partner) are estimated for the different pigmeat quarantine regimes implemented by Australia during the period 19882009. The welfare impact on consumers, producers, and foreign exporters is computed using a partial equilibrium model calibrated on the econometric estimates. The quarantine regimes have a strong effect on trade and welfare with a tariff equivalent above $113 \%$ of average real world prices over the period analyzed.
\end{abstract}

Keywords: pigmeat, pork, Australia, non-tariff measure, NTM, quarantine, import ban, trade JEL code: F13, F14, Q17

*This paper is part of research project FP7 KBBE.2008.1.4.05 "Assessment of the impacts of non-tariff measures NTM on the competitiveness of the EU and selected trade partners" under the $7^{\text {th }}$ Framework Program of the European Commission. The view expressed here should not be attributed to the European Commission. The authors thank guest editor, David Orden, an anonymous referee for comments and suggestions, and Chengyan Yue for help with R programming and project participants for their discussions and comments on previous drafts and presentations. Beghin acknowledges support of the Marlin Cole Fund at Iowa State University. Contact author: Beghin 260 Heady Hall, Economics. ISU Ames IA 50011-1030. USA beghin@iastate.edu. 


\section{INTRODUCTION}

Australia's import restrictions on pigmeat imports provide an interesting case study of non-tariff measures (NTMs). The recent trading history of this industry in Australia is characterized by the gradual and staged removal, since 1990, of long-standing and prohibitive quarantine measures. These barriers had permitted local pigmeat producers to dominate the domestic market. Their removal induced imports from Canada, then Denmark, and finally the United States. In 2004, Australia's pigmeat quarantine regime became the subject of a World Trade Organization (WTO) dispute that was eventually resolved with the decision to open Australia's pigmeat market to foreign producers who successfully pass a bespoke import risk analysis (WTO 2007). This paper helps quantify the differential burden imposed by Australia's quarantine regulations on producers based in Canada, Denmark and the United States.

Between 1990 and 2009 Australia went from being a net exporter of pigmeat to importing nearly $29 \%$ of its pigmeat consumption. Prior to 1990 , the only imports of pigmeat permitted into Australia were canned hams. By 2009, the Australian market for pigmeat had undergone significant trade liberalization. ${ }^{1}$ Imports are now, in principle, permitted from anywhere subject to a scientifically-based import risk analysis. This variation in NTM regimes, in particular the staged, country-by-country, relaxation of existing quarantine measures over time provides an opportunity to econometrically estimate the likely impact of Australia's ancien quarantine regime on individual pigmeat exporting countries.

Quarantine regulations represent the only significant policy barrier to the Australian market faced by pigmeat importers; Australia levies zero tariffs on imported pigmeat. The combination of negligible tariffs and restrictive quarantine is a characteristic of several agricultural and food markets in Australia. Indeed, quarantine measures are the most important

\footnotetext{
${ }^{1}$ See, for example, Tanner (1997), Tanner and Nunn (1998), Australian Government Productivity Commission (2008) and WTO (2007).
} 
class of NTMs imposed on several agricultural products (James and Anderson, 1998; Yue and Beghin, 2009). While Australia's relative geographic isolation ensures that distance is a potentially substantial source of (physical) trade cost and natural protection, the country's unique ecology magnifies concern over the risk of importing non-indigenous pests and disease.

Currently, the United States, Canada, and Denmark are the major sources of imports of pigmeat into Australia. There has been great variation in the market shares of these importers over time (Australian Government Productivity Commission, 2008). Other countries such as Brazil could potentially also export to Australia in future provided they first pass the required risk analysis. Australia's pigmeat policy experience is of particular importance to the European Union (EU). Denmark, an EU member, has consistently ranked as one of the three leading exporters of pigmeat into Australia since prohibitive quarantine regulations against its producers were relaxed at the end of 1997. Current quarantine regulations also allow EU members Finland, Germany, Italy, Spain and Sweden to export pigmeat to Australia although, thus far, the associated trade volumes have been small and sporadic. Variation in competitiveness among EU countries may partly explain this difference in bilateral trade flows with Australia. Many factors, apart from quarantine regimes, can influence the volume of pigmeat imports. While the rapid growth of Australian pigmeat imports is largely the result of domestic pigmeat production being replaced by imported product, strong market fundamentals such as population and income growth have also played an important role. Moreover, the unit cost of Australian pigmeat production has been variable because of severe droughts in the first decade of the $21^{\text {st }}$ century. The resulting volatility in feed costs has negatively impacted on the competitiveness of Australian pigmeat producers even while the nation's borders were being opened to foreign competition. In addition, the appreciation of the Australian dollar relative to other currencies has made imported pigmeat relatively cheap compared to locally-produced meat. It is anticipated that eventually the rate of growth of pigmeat imports will slow to reflect market fundamentals rather 
than policy changes (Australian Government Productivity Commission, 2008; ABARE, 2010).

Nevertheless, domestic producers have been pushing for safeguard actions to offset some of the competitive pressure from imports. In estimating the tariff equivalent of previous quarantine regimes, this paper provides some insight into the degree of protection formerly enjoyed by the domestic industry. Moreover, our approach sheds light on the impact on pigmeat imports of quarantine regulations relative to other factors.

\section{AUSTRALIA'S PIGMEAT TRADE POLICY}

Australia's trade policy with respect to imported pigmeat has undergone a number of changes over the last twenty years (Australian Government Productivity Commission, 2008). These changes fall into two main groups. First, there has been a gradual, country-by-country relaxation of Australia's quarantine regulations. Second, the EU initiated a WTO dispute (subsequently resolved) over Australia's quarantine procedures for imported pigmeat. This section provides a brief time line of the key changes in Australia's quarantine regime over time as well as a discussion of the WTO dispute and its resolution.

\section{a. Australia's recent quarantine regimes}

Pre-1990: No pigmeat imports are permitted except for canned hams.

May 1990: Imports of uncooked pigmeat are allowed from New Zealand (NZ), a marginal exporter of pigmeat.

July 1990: Imports of uncooked (frozen) pigmeat are allowed from Canada, a major exporter. Canadian import growth is minimal despite this significant liberalization.

Late 1992: Uncooked (frozen) pigmeat from Canada must also be boned prior to export and processed on arrival under quarantine control. This was a likely attempt to stem Canadian imports by imposing a stricter restriction. 
May 1996: Unfrozen pigmeat imports are allowed from Canada if they are boned and cooked on arrival under quarantine control. This is a further step in the relaxation of the SPS regime toward Canada and its exports levels to Australia increase.

November 1997: (i) Uncooked, boneless pigmeat imports are allowed from Denmark if they are processed on arrival under quarantine control. This represents a major liberalization vis-à-vis Denmark. Danish imports were banned before this.

(ii) Canadian pigmeat that has been cooked and boned prior to export can be imported into Australia. This change represents a further liberalization of pigmeat trade with Canada.

From 2004 onwards: Imports from anywhere permitted provided appropriate risk management is undertaken (this is defined on a country-specific basis). Only a few countries have undertaken the import risk analysis including Canada, Denmark, USA, Finland, Germany, Spain, and Italy. May-July 2004: Danish pigmeat that has been frozen, cooked and boned prior to export can be imported into Australia provided that major peripheral lymph nodes have been removed. Similar conditions apply for imports from Canada and the United States; the meat must be processed on arrival under quarantine control. In summary, all imports coming to Australia have to be processed and cannot compete in the fresh pigmeat market uniquely served by domestic supplies. Imports from all other countries are currently banned as they have not undertaken a risk analysis.

\section{b. The WTO dispute}

In April 2003, the EC requested consultations with Australia regarding the Australian quarantine regime for imports of pigmeat. Consultation is a necessary first step in the WTO's dispute resolution mechanism. The EC complained that the Australian quarantine regime for imports appeared to be discretionary and arbitrary because it was left to the discretion of a director of the Australian quarantine service. More importantly, the absence of risk assessment made the $a$ priori ban in imports suspect, because it lacked any scientific basis.

The Australian approach is to delay risk assessment until the import of a product has been 
specifically requested. In some cases, no risk assessment had commenced despite an import request having been received. The EC request for consultation claimed that in 2003 Australia permitted the import of deboned pigmeat from Denmark for processing in Australia but not of processed deboned pigmeat from Denmark. Processing requirements imposed in Australia to protect Australia from PRRS (Porcine Reproductive and Respiratory Syndrome) were claimed to be overly restrictive. Requests for market access to Australia for processed pigmeat or deboned pigmeat from other EU Member States were also turned down.

Canada, Chile, India, and the Philippines requested to join the initial consultations. In August 2003, the EC requested the establishment of a panel that was initially deferred but eventually accepted by the WTO. The Dispute Settlement Board established a panel at its meeting on 7 November 2003. Canada, Chile, China, India, Philippines, Thailand, and the United States reserved their third-party rights.

In 2004, Australia's Quarantine Inspection Service (AQIS) issued a draft import risk analysis on pigmeat, which clarified many of the contentious issues at the core of the dispute. This import risk analysis was finalized and became the basis of current quarantine regulations on pigmeat imports. In March 2007, Australia and the European Communities notified the Dispute Settlement Body of the WTO that they had reached a mutually agreed solution to address the issues identified by the EC, providing an acceptable level of protection for Australia and consistent with Australia's SPS legislation and import policy development process.

The analysis undertaken in the following sections quantifies the trade and welfare impact of the changes to Australia's pigmeat quarantine regimes described above (including those induced by the WTO dispute). We focus on quarantine and ban policies since these measures are 
the key trade barriers (tariffs are zero) on most pork products imported into Australia. ${ }^{2}$ The consensus view is that bans and their progressive relaxation have been the binding policy constraint on imports rather than other forms of non-tariff measures (Australian Government Productivity Commission, 2008). In what follows, we analyze the relative competitiveness of the three significant exporters to Australia (Denmark, Canada, the United States), following the progressive opening of the Australian market. Several interesting questions arise: To what extent did exporters actually benefit from the Australian market opening? What were the gains to Australian consumers? What are the other determinants of pigmeat demand?

Our analysis accounts for domestic supply shocks embodied in the unit cost of Australian pigmeat production. Similarly, exchange rate movements between Australia and these pigmeat exporters have had a significant impact on bilateral trade flows. We incorporate these exchange rate changes as well as their effects on relative prices and cross-price effects in pigmeat demand.

\section{METHODOLOGY}

Following Yue and Beghin (2009) and Yue et al. (2006), we use a combination of econometric investigation and a multimarket simulation model calibrated with the econometrically estimated parameters. The econometric estimation centers on estimating an import demand system for pigmeat accounting for corners in demand (i.e. zero consumption) and import decisions. Our conjecture is that these "zeros" are induced by prohibitive trade costs imposed on lower unit prices for pigmeat sourced from more competitive countries. The simulation component is based on a multi-market model, which includes the supply of pigmeat in the key countries of Australia, Denmark, Canada and the United States, coupled with the previously estimated import demand

\footnotetext{
${ }^{2}$ Tariffs on pigmeat imported into Australia were bound at zero as part of the WTO Uruguay Round Agreement in 1995.
} 
system. The model allows us to simulate the impact of policy changes, such as the subsequent removal of prohibitive trade impediments, on pigmeat trade.

\section{a. Conceptual model for the estimation of a prohibitive quarantine NTM regime}

As discussed in the previous section, Australian pigmeat imports have been subject to multiple quarantine regimes since 1990. Not only have these regimes varied over time but, moreover, multiple different regimes, based on the identity of the importing country, have operated concurrently. Note that this is in contrast to the New Zealand apples case addressed in Yue and Beghin (2009) that involved a single-country ban, which, moreover, never varied over the life of the data period under consideration. In other words, we have time-variation in trade regimes for a number of exporting countries as well as cross-sectional variation in quarantine regime applied to countries that export pigmeat to Australia. In contrast, only the latter type of variation was present in Yue and Beghin (2009). The additional source of variation that we make use of in this study should result in more robust estimation of the tariff equivalents than has been possible in previous work.

As in Yue and Beghin (2009), our methodology is based on Wales and Woodland (1983) who use Kuhn-Tucker conditions to characterize corner solutions in consumption based on a random utility model (RUM). Applications to trade are limited, although attention to corner solutions (zero trade) has recently become a preoccupation of the trade literature (Helpman, Melitz, and Rubinstein (2008); Chaney (2008)). This literature seeks to explain why firms decide to export (or not). The focus, therefore, is on trade's extensive margins (i.e. new trade rather than intensification of existing trade flows) from the producer side. In this paper, our conjecture is that the absence of trade arises from the consumer/importer side. Latent supply is available; if the trade ban were to be lifted, consumption would (and, in fact, did) take place.

Our estimation strategy draws on the approach of Wales and Woodland (1983) and introduces some modifications to the methodology as applied by Yue and Beghin (2009). The 
underlying preferences follow the linear expenditure system (LES), which has well known limitations on price and income responses but nevertheless represents the state of the art in applied RUMs with corner solution (see Phaneuf et al. 2000). The LES implies that goods are substitutes, which is consistent with our pigmeat investigation presumably. Addressing the zeros in import decisions for a consumer's perspective and not imposing Armington assumptions is a novel departure.

The representative pigmeat consumer in a given country $k$ maximizes utility from consuming market goods $\left(\mathbf{x}_{k}, A O G_{k}\right)$ subject to their budget constraint, i.e.,

$$
\begin{gathered}
\underset{\mathbf{x}_{k}, A O G_{k}}{\operatorname{Max}_{k}} U_{k}\left(\mathbf{x}_{k}, A O G_{k} \mid \mathbf{y}_{k}, \delta, \eta, \boldsymbol{\varepsilon}_{k}, \omega\right)=\sum_{j=1}^{M} \psi_{j}\left(\mathbf{y}_{k}, \eta_{j}, \delta_{j}, \varepsilon_{j k}\right) \ln \left(x_{j k}+\omega_{j}\right)+v\left(A O G_{k}\right) \\
\text { s.t. } \mathbf{p}_{k}^{\prime} \mathbf{x}_{k}+A O G_{k} \leq I_{k}, \\
A O G_{k} \geq 0, \\
\mathbf{x}_{k} \geq 0,
\end{gathered}
$$

where $\mathbf{x}_{k}=\left(x_{1 k}, \ldots, x_{M k}\right)^{\prime}$ is the vector of pigmeat consumption differentiated by sources 1 to $M$; $A O G_{k}$ is a composite good which aggregates expenditure on all-other-goods; $\mathbf{y}_{\boldsymbol{k}}$ is a vector of socio-demographic information of consumers in importing country $k$ defining preferences for $\mathbf{x}_{k}$ through parameters $\boldsymbol{\eta}$; vector $\boldsymbol{\delta}$ is the vector of preferences for attributes of $\mathbf{x}_{k}$ other than sociodemographics (country of origin, for example). Vector $\boldsymbol{\varepsilon}_{k}=\left(\varepsilon_{1 k}, \ldots, \varepsilon_{M k}\right)^{\prime}$ is a vector of random components capturing preference variation known to the consumers in country $k$ but not known to the researcher. This is the essence of the random utility model. Vector $\boldsymbol{\omega}$ characterizes taste parameters capturing minimum consumption thresholds. Preference weight functions $\psi_{j}\left(\mathrm{y}_{k}, \eta_{j}, \delta_{j}, \varepsilon_{j k}\right)=\eta_{j}^{\prime} \mathbf{y}_{k}+\delta_{j}+\varepsilon_{j k}$ represent consumers' preference in the importing country for $\operatorname{good} j$. Function $v$ relates $A O G$ to the consumer's utility and represents the utility of income; in our case it is defined as $v\left(A O G_{k}\right)=\psi_{A O G} \ln \left(A O G_{k}\right)$. 
Vector $\mathbf{p}_{k}=\left(p_{1 k}, \ldots, p_{M k}\right)^{\prime}$ represents final consumer real prices in local currency faced by consumers of pigmeat in country $k$, inclusive of trade costs (transportation, trade barriers, and other transaction costs); variable $I_{k}$ is the real income of the representative consumer in country $k$. The composite (all-other-expenditure) good price is normalized to 1 ( $A O G$ it is the numéraire).

Consumer prices in country $k$ are made of an export unit cost of pigmeat common to all destinations for that exporter and additional trade costs arising from distance (transportation cost), tariffs, and NTMs such as quarantine regimes. For pigmeat type $j$, this consumer price in any country $k$ is a bilateral price $p_{j k}=\left(w p_{j}+\gamma d_{j k}\right) * E R_{j k}+t_{j k}+N T M_{j k}+O T C_{j k}$, where $\mathbf{w p}=\left(w p_{1}, \ldots, w p_{M}\right)$ 'is the vector of world prices/export unit costs for pigmeat consumption $\mathbf{x}$. The latter prices are common to all export destinations for any given source $j$. Component $\gamma d_{j k}$ is the transportation cost to bring pigmeat $j$ (i.e., sourced in country $j$ ) to the importing country $k$. Vector $\mathbf{d}_{k}=\left(d_{1 k}, \ldots, d_{M k}\right)^{\prime}$ is the vector of bilateral distances between each pigmeat source and the importing country $k$ under consideration, and $\gamma$ is the unit rate of transportation cost and associated fees. The unit rate is assumed to be the same per unit of distance across all trade flows of pigmeat. The latter assumption is reasonable because different types of pigmeat tend to be similar in terms of their transportation characteristics. Transportation cost is expressed as a perunit cost rather than in ad valorem form ( $\%$ of unit price). This specific tax form of shipping cost tends to perform better econometrically relative to an ad-valorem one (Hummels and Skiba, 2004). Variable $E R_{j k}$ is the exchange rate between country $k$ and country $j$. Vector $\mathbf{t}_{k}=\left(t_{1 k}, \mathrm{~L}, t_{M k}\right)$ is the vector of specific bilateral tariffs imposed by the importing country $k$ on all foreign goods; vector $\mathbf{N T M}_{k}=\left(N T M_{1 k}, \ldots, N T M_{M k}\right)$ ' represents the specific tariff equivalent of prohibitive NTMs, such as the Australian quarantine measures, imposed on exports from countries 1 to $M$ by the importing country $k$. Here, $\mathbf{N T M}_{k}$ exhibits time variation because the quarantine regime is sequentially liberalized. 
These trade restrictions raise the unit cost of products in the importing country. Variable $O T C_{j k}$ represents the specific trade cost components associated with other trade costs between countries $j$ and $k$ such as cultural cost (common language etc). The corresponding vector OTC $_{k}$ can be defined as well paralleling the $\mathbf{N T M}_{k}$ vector.

Solving the consumer's utility constrained maximization problem in country $k$ yields necessary and sufficient Kuhn-Tucker conditions of the form:

$$
\begin{gathered}
U_{k x_{j k}}\left(\mathbf{x}_{k}, A O G_{k} \mid \mathbf{y}_{k}, \delta, \eta, \varepsilon, \omega\right)=\frac{\partial U_{k}(.)}{\partial x_{j k}} \leq \lambda p_{j k}, x_{j k} \geq 0 \\
x_{j k}\left[U_{k x_{j k}}(.)-\lambda p_{j k}\right]=0, j=1, \mathrm{~L}, M \\
U_{k A O G_{k}}\left(A O G_{k}\right)=\frac{\partial U_{k}(.)}{\partial A O G_{k}}=\frac{\partial v\left(A O G_{k}\right)}{\partial A O G_{k}}=v^{\prime}\left(A O G_{k}\right)=\psi_{A O G} / A O G_{k} \leq \lambda, A O G_{k} \geq 0, \\
A O G_{k}\left[U_{k A O G_{k}}(.)-\lambda\right]=0,
\end{gathered}
$$

with $U_{k x_{j k}}()=.\frac{\psi_{j}\left(\mathrm{y}_{k}, \eta_{j}, \delta_{j}, \varepsilon_{j k}\right)}{x_{j k}+\omega_{j}}=\frac{\left(\eta_{j}{ }^{\prime} \mathrm{y}_{k}+\delta_{j}+\varepsilon_{j k}\right)}{x_{j k}+\omega_{j}}$, and with $\lambda$ being the marginal utility of income. The consumption of the numéraire good is assumed strictly positive, i.e., $A O G_{k}>0$. Substituting (4) into (2) and (3) yields

$$
\begin{gathered}
U_{k x_{j k}}(.)=\frac{\left(\eta_{j}^{\prime} \mathbf{y}_{k}+\delta_{j}+\varepsilon_{j k}\right)}{x_{j k}+\omega_{j}}=v^{\prime}\left(A O G_{k}\right) p_{j k} \text { when } x_{j k}>0 \\
U_{k x_{j k}}(.)=\frac{\left(\eta_{j}^{\prime} \mathbf{y}_{k}+\delta_{j}+\varepsilon_{j k}\right)}{x_{j k}+\omega_{j}} \leq v^{\prime}\left(A O G_{k}\right) p_{j k} \text { when } x_{j k}=0
\end{gathered}
$$

Terms are reordered in equations (6) and (7) and prices are fully expressed, leading to

$$
\varepsilon_{j k}=g_{j k}\left(\mathbf{x}_{k} \mid \mathbf{y}_{k}, \mathbf{w p}, \mathbf{d}_{k}, \mathbf{t}_{k}, \mathbf{N T M} \mathbf{M}_{k}, O T C_{k}, \delta, \omega, \gamma, \eta_{j}\right) \text { when } x_{j}>0
$$

and

$$
\varepsilon_{j k} \leq g_{j k}\left(\mathbf{x}_{k} \mid \mathbf{y}_{k}, \mathbf{w p}, \mathbf{d}_{k}, \mathbf{t}_{k}, \mathbf{N T M} \mathbf{M}_{k}, O T C_{k}, \delta, \omega, \gamma, \eta_{j}\right) \text { when } x_{j}=0
$$

with 


$$
\begin{aligned}
& g_{j k}\left(\mathbf{x}_{k} \mid \mathbf{y}_{k}, \mathbf{w p}, \mathbf{d}_{k}, \mathbf{t}_{k}, \mathbf{N T M} \mathbf{M}_{k}, O T C_{k}, \delta, \omega, \gamma, \eta_{j}\right)= \\
& {\left[v^{\prime}\left(A O G_{k}\right)\left(\left(w p_{j}+\gamma d_{j k}\right) E R_{j k}+t_{j k}+N T M_{j k}+O T C_{j k}\right)\left(x_{j k}+\omega_{j}\right)\right]-\left(\delta_{j}+\eta_{j}^{\prime} \mathbf{y}_{k}\right) .}
\end{aligned}
$$

The computation of the log-likelihood function requires the derivatives of functions $\mathbf{g}$ with respect to $\mathbf{x}$, i.e.,

$$
\begin{aligned}
& \partial g_{j k} / \partial x_{j k}=\left[v^{\prime}\left(A O G_{k}\right)\left(\left(w p_{j}+\gamma d_{j k}\right) E R_{j k}+t_{j k}+N T M_{j k}+O T C_{j k}\right)\right]+ \\
& {\left[\left(\left(w p_{j}+\gamma d_{j k}\right) E R_{j k}+t_{j k}+N T M_{j k}+O T C_{j k}\right)\left(x_{j k}+\omega_{j}\right) \partial v^{\prime}\left(A O G_{k}\right) / \partial x_{j k}\right], \text { with }} \\
& \partial v^{\prime}\left(A O G_{k}\right) / \partial x_{j k}=v^{\prime}\left(A O G_{k}\right)\left(\left(w p_{j}+\gamma d_{j k}\right) E R_{j k}+t_{j k}+N T M_{j k}+O T C_{j k}\right) / A O G_{k} .
\end{aligned}
$$

The specification of the joint density function $f_{\varepsilon}\left(\boldsymbol{\varepsilon}_{k}\right)$ together with the above expressions of $\varepsilon_{j k}$ provides necessary information to set up the likelihood function for estimation. Suppose a given consumer's consumption of the first $G$ commodities' is zero, while consumption is positive for the remaining $G+1$ to $M$ commodities (that is, $x_{j k}=0, j=1, \ldots G$ and $x_{j k}>0, j=G+1, \ldots M$ ). Then, this $k$ 'th consumer s contribution to the likelihood function is given by the following probability $f_{k}$ :

$$
f_{k}=\int_{-\infty}^{g_{1 k}} \cdots \int_{-\infty}^{g_{G k}} f_{\varepsilon}\left(\varepsilon_{1 k}, \cdots, \varepsilon_{G k}, g_{G+1 k}, \cdots, g_{M k}\right) \times|J| d \varepsilon_{1 k} \cdots d \varepsilon_{G k}
$$

where $\boldsymbol{J}$ denotes the determinant of the Jacobian matrix for the transformation from $\boldsymbol{\varepsilon}_{k}$ to $\left(\varepsilon_{1 k}, \cdots, \varepsilon_{G k}, X_{G+1 k}, \cdots, X_{M k}\right)$

We assume that the $\varepsilon_{j k}$ errors are identical and independent, and follow the standard normal distribution. Assuming $N$ available observations, we use the following log-likelihood function to estimate the specific tariff equivalent of NTM, OTC, and parameters $\boldsymbol{\delta}, \boldsymbol{\omega}, \gamma$, and $\boldsymbol{\eta}$

$$
l=\sum_{i=1}^{N}\left(\sum_{j=1}^{G_{i}} \ln \left(\Phi_{i}\left(g_{j}\right)\right)+\sum_{j=G_{i}+1}^{M} \ln \left(\phi_{i}\left(g_{j}\right)\right)+\ln \left|\boldsymbol{J}_{i}\right|\right)
$$

where $i$ indicates observation $i(i=1, \ldots, N)$; and $j$ is commodity $j(j=1, \ldots, M)$; $\Phi$ is the cumulative density function of standard normal distribution for the goods that are not consumed, and $\phi$ is the density function of standard normal distribution for the goods that are consumed. 
Some additional structure is implied by these assumptions. Whenever a consumption of $\operatorname{good} j$ in a given country has all its observations strictly positive, the mean of its $g_{j}$ function is equal to zero since $\varepsilon_{j}=g_{j}$ as implied by equation (8), or

$\psi_{j}=E\left[\left(x_{j k}+\omega_{j}\right)\left(\psi_{A O G} / A O G_{k}\right)\left(\left(w p_{j}+\gamma d_{j k}\right) E R_{j k}+t_{j k}+N T M_{j k}+O T C_{j k}\right)\right]$

Restriction (14) can be imposed on the data and implies a relationship between $\psi_{j}, \omega_{j}$, and $\psi_{A O G}$. In addition, the utility weights $\psi$ can be normalized with one of the weights set equal to 1 .

\section{DATA}

Initially we planned to estimate a global demand system using global pigmeat trade and consumption data. However, multiple data issues prevented assembling such a complete dataset and undertaking such estimation. Instead, we focus on Australia as the importer (hence $k=$ Australia) and its major trade partners that are exporters of pigmeat, namely, Canada, Denmark, and the United States. There are negligible exports from NZ and more recently from a variety of EU countries (Italy, Spain for example) to Australia, but the volumes involved are too small and sporadic to be considered systematically.

The data are collected for 1988 to 2009 and come from various sources. Bilateral trade volume and unit values come from COMTRADE via WITS and are expressed in local currencies. We collected data for "meat of swine, fresh, chilled, or frozen" (HS 0203), the only type of pork product eventually allowed in Australia. We focus on four distinct countries: Australia, Denmark, Canada and the United States. We use import unit values for trade flows from Denmark, Canada, and USA to Australia; hence, we do not include a distance variable into the final consumer price as the import unit value already includes international transportation cost. For Australia's domestic cost we use its average export unit value to the world as the representative price. All prices are deflated by the Australian GDP deflator at 2005 prices. 
While bilateral tariff data are available from WITS there are many missing observations for pre- Uruguay Round Agreement years (1988-1994), and the data are often inconsistent suggesting inaccuracies. As a result, we do not use tariff in the estimations that follow. Since Australian tariffs are bound to zero starting in 1995 and presumably equally applied to all countries this omission is unlikely to be significant. Moreover, time fixed effects can capture the missing tariff effects, if any. The pigmeat consumption data come from the FAO (FAO code 2733) and covers all pork processed domestically. Domestic consumption of Australian pigmeat is defined as pigmeat food supply net of exports to the world (under HS 0203).

For the quarantine regime variables we consider four regimes. Three regimes correspond to the impediments affecting Canadian, Danish, and U.S. imports. Canadian imports were prohibited in 1988-89 and then liberalized progressively starting in 1990. Danish imports were allowed starting in 1997; finally, U.S. imports have been permitted since 2004. Additionally, in early 2007, the WTO dispute brought by the EC against Australia was officially resolved and trade flows continued to expand thereafter.

Figures 1 and 2 show that Canadian imports were only partially liberalized in 1990 and that they benefited from the further relaxations undertaken in 1997 and 2004. Similarly, Danish imports further benefited from the 2004 reforms. Accordingly, we consider the three country liberalizations as cumulative for Canada since it was the first one to be liberalized. We posit that the 1997 and 2004 regimes changes benefited Danish imports, and finally we assume that U.S. imports were liberalized last and only benefited from this last regime change starting in 2004 . Three dummy variables $T B T_{j t}$ for pigmeat from country $j$ (Canada, Denmark, and USA) and year $t$ (1988-2009) define the 3 successive regimes (Canada banned 1988-1989, allowed 1990 onwards; Denmark banned 1988-1996, allowed 1997 onwards; and USA banned 1988-2003, allowed 2004 onwards). In addition, we investigate the potential effect of a WTO TBT dummy (1 until 2006, 0 onward) to capture the fourth element of the quarantine reforms in the Australian 
pigmeat market on these three import sources. The latter variable is potentially not entirely independent since the 2004 reforms already reflect many of the reforms made official in 2007.

For variable OTC we rely on CEPII data on common language and other cultural and geographical sources of transaction cost. In fact, these variables turn out to be insignificant and are omitted from the final estimation model. This problem may originate from the relative cultural uniformity between these trading countries and the limited country variation in our smaller dataset. If the analysis undertaken in this paper were to be expanded to account for a broader range of heterogeneous exporters (Brazil and China, for example) the OTC variables should be retained in the final estimation.

\section{EMPIRICAL SPECIFICATION AND ECONOMETRIC RESULTS}

Consistent with the discussion in the preceding section, we define four prices for Australian, Canadian, Danish, and U.S. pigmeat for year $t$ and in local currencies respectively as follows:

$$
\begin{aligned}
& p_{\text {austt }}=\text { average export unit value } \text { austt }_{\text {ant }}, \\
& p_{\text {cant }}=\text { import unit value }_{\text {cant }}+N T M_{\text {can }}\left(T B T_{\text {cant }}+T B T_{d n k t}+T B T_{u s t}+T B T_{w t o}\right) / 4, \\
& p_{d n k t}=\text { import unit value }_{d n k t}+N T M_{d n k}\left(T B T_{d n k t}+T B T_{u s t}+T B T_{w t o}\right) / 3, \\
& p_{u s a t}=\text { import unit value }_{u s a t}+N T M_{u s a}\left(T B T_{u s a t}+T B T_{w t o}\right) / 2 .
\end{aligned}
$$

Equation (15) shows that the price of pigmeat imported from any particular country depends, not only on TBT imposed by Australia on that country, but also on the TBT still imposed on other foreign pigmeat when that particular country's TBT is lifted. For example, the price of Canadian pigmeat in Australia depends not just on those TBTs imposed on Canadian pigmeat, but also those imposed on Danish and US producers which were lifted later, as well as on any additional barriers that were only removed after the late resolution of the WTO dispute. The justification for the price relationships stipulated in equation (15) is based on the fact that, the data show that already liberalized imports expanded even further once other TBTs were subsequently removed. 
The subsequent liberalizations appear to have led to a decrease of trade cost impediments for all imports already admitted.

As also suggested in Figure 1, Canadian, U.S. and, to a lesser extent, Danish pigmeat imports, initially increased slowly before accelerating in the years following the initial relaxation in quarantine regimes. For this reason, we investigate the significance of $T B T$ variables lagged by six months and one year in an attempt to capture the apparent delay in the market response to the regulatory changes.

Since we focus only on imports into a single importer - Australia - we simplify the preference weights to be equal to a constant defined as $\psi_{j}\left(\delta_{j}, \varepsilon_{\text {jaust }}\right)=\delta_{j}+\varepsilon_{\text {jaust }}$. In addition, we impose condition (14) on Australian pigmeat consumption in Australia since all its observations are strictly positive. This constraint is expressed as $\psi_{j}=E\left[\left(x_{\text {jaustt }}+\omega_{j}\right)\left(\psi_{A O G} / A O G_{\text {aust }}\right) p_{j t}\right]$ for $j=$ aust. We also normalize the preference weight on domestic pigmeat to be equal to 1, as explained previously and, moreover, assume equal autonomous consumption for imported pigmeat, i.e. $\omega_{c a n}=\omega_{d n k}=\omega_{u s a}=\omega_{i m p}$. Table 1 shows our three preferred estimations for the cases of no-lag in quarantine variables, a six-month lag, and a one-year lag respectively to capture the apparent delayed reaction of the market to changes in quarantine policy changes. $^{3}$

\section{$<$ Table 1 about here $>$}

In each of the three specifications, all parameters are statistically significant at the $5 \%$ level. The NTM estimates correspond to high ad-valorem equivalent, expressed in percent of real border price (import unit value). They are all higher than 113\% (expressed as a proportion of the average real import unit price for the 1988-2009 period). Using other reference prices would lead to different AVE estimates, but regardless of the reference prices, the AVE estimates remain

\footnotetext{
${ }^{3}$ The $R$ code written to implement this estimation is available from the authors on request.
} 
large. The NTM estimates, expressed in specific terms, that is, in Australian Dollars per unit, are highest for U.S.-sourced pigmeat (between AU\$11.08/kg and 16.46/kg), followed by Canada (AU\$8.86/kg to AU\$12.27/kg), and Denmark (AU\$5.96/kg and AU\$8.69/kg). The six-month lag specification yields the largest NTM estimates for all three countries that are the subject of our analysis.

Recall that these NTM estimates correspond to the cumulative effect of the WTO NTM dispute resolution, the change all three quarantine regime changes (in 1990, 1997, 2004) for Canadian imports, two quarantine regime changes $(1997,2004)$ for Danish imports and, for U.S. imports, only the 2004 regime change. Introducing the dichotomous variable for the WTO dispute resolution as an independent episode of liberalization with its own coefficient leads to larger standard deviations, especially for the U.S. NTM. For that reason, we constrain the WTO NTM coefficient to be equal to the coefficient for the other NTM regimes as shown in equation (15).

The preferences weight estimates, $\psi_{j}=\delta_{j}$, show that relative to the domestic pigmeat (with a weight normalized to 1), all imported pigmeat types exhibit weights larger than 1 , and among imports, Canadian-sourced pigmeat is preferred to Danish and U.S. pigmeat. The latter two weights are nearly equal and their ordering varies in some runs as suggested by Table 1 . The preference weight for $A O G$ is large because of the scale of $A O G$ (close to personal income) as suggested by equation (14). The autonomous consumption parameter estimates, $\omega$, show a negative value, which is rather large in absolute value, for the domestic pigmeat, and a small positive estimate for the imported meats. The sign of the latter is expected as many observations for imported meats are zeros or small. The large magnitude in absolute value of the domestic autonomous consumption, $\omega_{\text {aust }}$, is explained by the first order conditions yielding ratios $\left(\delta_{j} / \delta_{i}\right)\left(x_{i}+\omega_{i}\right) /\left(x_{j}+\omega_{j}\right)=p_{j} / p_{i}$. The relative price is approximately equal to 1 and the average 
domestic consumption approximately $18 \mathrm{~kg}$. Hence, the large magnitude of $\omega_{\text {aust }}$ offsets the large consumption to bring the ratio close to 1 , abstracting from the relative preference weights. All these parameters are interdependent in the estimation. We also ran specifications without the constraint of equal autonomous consumptions among imports, but this produces unstable results for the estimate of $N T M_{u s a}$, which becomes large and with increasing variance.

\section{a. Welfare analysis approach}

We use the results in Table 1 ( $2^{\text {nd }}$ specification) to parameterize a small partial equilibrium model accounting for Australian domestic demand and supply of pigmeat, as the (Australian) demand for and (foreign) supply of Canadian, Danish, and U.S. pigmeat. We follow recent analyses of technical barriers to trade and SPS policies by Yue et al. (2006), Yue and Beghin (2009), and Peterson and Orden (2008) in terms of the general approach, but with additional assumptions relevant to the case studied here. In particular, we assume that Australia is a small country facing parametric world prices at the border for pigmeat from Canada, Denmark, and the United States. We assume, furthermore, that Australia's domestic pigmeat supply is inelastic and that the Australian pigmeat price is endogenous and determined by market equilibrium for Australian-produced pigmeat. As the second specification in Table 1 yields the largest tariff equivalent of the NTM effects among the 3 specifications, our welfare estimates for the consumer and the trade expansion are also the largest of the 3 specifications reported in Table 1.

Australian pigmeat producers experienced profit losses when pigmeat imports expanded as a result of the three major changes in quarantine policy identified earlier. These policy changes are simulated here by the removal of the tariff equivalents. This removal affects suppliers of Australian pigmeat and their profit (producer surplus). Variable $S_{A U}$ is the domestic supply of Australian pigmeat. It is an increasing function of domestic pigmeat price and exogenous parameter $v$ and is characterized by constant elasticity $\lambda_{S}$ : 


$$
S_{\text {aust }}\left(p_{\text {aust }}, v\right)=v p_{\text {aust }}^{\lambda_{S}}
$$

Parameter $v$ is used to calibrate the supply to the reference market data chosen for the policy scenario. The equilibrium domestic pigmeat price $p_{\text {aust }}$ and quantity are determined by equilibrium in the domestic pigmeat market, i.e.

$$
S_{\text {aust }}\left(p_{\text {aust }}^{\mathrm{e}}, v\right)=X_{\text {aust }}\left(p_{\text {aust }}^{\mathrm{e}}, p_{\text {can }}, p_{\text {dnk }}, p_{\text {usa }}\right)
$$

The aggregate Australian demand for domestic pigmeat at time $t, X_{\text {aust }}\left(p_{\text {aust }}^{e}, p_{\text {can }}, p_{\text {dnk }}, p_{\text {usa }}\right)$, is the product of per capita demand for the same pigmeat (derived from first order conditions (6)) and the Australian population for the same year. When per capita demands are positive they take the form

$x_{i}=-\omega_{i}+\psi_{i}\left[I+\omega_{\text {aust }} p_{\text {aust }}+\omega_{i m p}\left(p_{d n k}+p_{c a n}+p_{u s}\right)\right] /\left[p_{i}\left(\psi_{c a n}+\psi_{d n k}+\psi_{u s}+\psi_{A O G}\right)\right]$

for $i=a u s t$, can, dnk, us.

With the changes in quarantine regimes, the internal prices of imported pigmeat decrease and demand for Australian pigmeat shifts to the left, lowering the equilibrium Australian pigmeat price and quantity exchanged. Pigmeat imports from Denmark, Canada and the United States expand since the direct effect of the lower own price is stronger than the feedback effect of the lower Australian pigmeat price via cross price responses.

Next, the compensating variation $(\mathrm{CV})$ of the Australian representative consumer is computed from the utility function specified in equation (1). There is no explicit function for the $\mathrm{CV}$. We use a bisection to compute the CV that equates the utility of the consumption at new prices and original income net of the $\mathrm{CV}$ and the utility of the original consumption vector (evaluated at original prices and income). ${ }^{4}$

\footnotetext{
${ }^{4}$ The $\mathrm{CV}$ and producer surplus are nonlinear in the estimated parameters resulting in potential bias in the $\mathrm{CV}$ and producer surplus estimates. This bias could be addressed using the computing strategy of Yue and Beghin (2009) to generate empirical distributions for the welfare measures and trade effects rather than point estimates.
} 


\section{b. Welfare analysis results}

Table 2 shows the computed welfare and trade effects. ${ }^{5}$

$<$ Table 2 about here $>$

The welfare and trade effects are based on 2003 initial levels of domestic consumption and prices, and the regression estimates. The year 2003 was chosen because it is the last year prior to the large liberalization of 2004 with U.S imports and associated large expansion in both Canadian and Danish imports. We assume that initial trade is nonexistent and then remove the country-specific NTM tariff equivalent (specific) rate from the prices to gauge the trade expansion and contraction of domestic pigmeat consumption. Note that income and population levels in 2003 are also fairly close to their current levels. Nevertheless, it is possible to use any other year under some quarantine regime to calibrate the welfare trade effects.

The consumers' welfare gains from removing the NTM tax equivalents are about AU\$20 per capita or AU\$409 million for the Australian economy. Consumption of imported pigmeat grows to $5.26 \mathrm{~kg}$ per person or 104.66 thousand metric tons. The impact on the domestic pigmeat market is limited. This arises because cross-price effects are limited and there is a strong income effect that leads to negligible net (i.e. after accounting for substitution and income effect) decreases in domestic quantities consumed and produced. Note that the functional form chosen for the random utility model may also cause small cross- price effects by design as suggested by equation (18). The cross price effects depend on 5 parameter estimates, 2 prices and pigmeat quantity. Hence it is difficult to exactly pin down the exact effect of the functional form choice. Other functional forms could lead to stronger cross-price effects and stronger local market effects. Export revenues to Australia expand by nearly AU\$245 million, AU\$109 million, and AU\$125 million for Canadian, Danish, and US pigmeat respectively.

\footnotetext{
${ }^{5}$ The $R$ code written to implement this welfare analysis is available from the authors on request.
} 


\section{c. Decomposition analysis}

Finally, we take a long-term view of the 1988-2009 evolution of the pigmeat market in Australia by providing a decomposition of growth and changes as in Heien and Wessells (1988). Total pigmeat consumption in Australia increased by nearly $61 \%$ during the period being studied. Demographic growth contributes the most to the total increase but changes in per capita consumption also matter, and reflect underlying market fundamentals (such as prices, income). The $61 \%$ expansion is the sum of $32 \%$ from population growth, $22 \%$ from consumption per capita growth and their joint effect, 7\% (rounded). Composition changes are also considerable. The $22 \%$ increase in consumption per capita when decomposed by source shows that domestic (Australian) pigmeat consumption per capita actually decreased during this period by $13 \%$, and that pigmeat imports which were non-existent in 1988 grew, by 2009 , to represent nearly $35 \%$ of the initial 1988 domestic pigmeat consumption per capita $(22 \%=-13 \%+35 \%)$. The $35 \%$ further decomposes into $13 \%, 11 \%$, and $11 \%$ for imports from Denmark, Canada, and the United States.

During the period 1988-2009, consumption per capita grew as a result of the unit price decreases that occurred with productivity gains in pigmeat production and trade liberalization, and also from growth in income. Over this period, income per capita grew by $54 \%$. Assessing the role of income is a bit more complicate as the composition of the meat consumed changed over time and as the imported meat consumption grew from a zero initial consumption. The domestic meat consumption has a low elasticity of income (0.08), which led to a $5 \%$ increase induced by income growth. As this consumption actually fell by $13 \%$ over the 22 years, the effect of prices and competition from imports was approximately $-18 \%(-13 \%-5 \%=-18 \%)$ and were mitigated by income growth.

Imports have a much higher income elasticity coming from their higher preference parameters and lower consumption levels which enter in the denominator of the income elasticity. Income growth from 1999 to 2009 was responsible for $19 \%$ of the Danish pigmeat 
consumption in 2009; income growth from 1990 to 2009 was responsible for $40 \%$ of the Canadian pigmeat consumption in 2009; and income growth from 2004 to 2009 was responsible for $28 \%$ of the consumption of U.S. pigmeat. All income elasticities were evaluated at 2009 levels to compute these effects. The remainder of the per capita consumption growth of imported pigmeat comes from price changes following the NTM reforms. All unit costs fell over time from new technologies in pork production, and the removal of the quarantine regimes also induced a substantial decrease in imported pigmeat prices as explained previously. Hence, trade liberalization, productivity gains, and income all play an important role in explaining per capita pigmeat consumption changes. Nevertheless, all these influences are dominated by the significant population growth experienced by Australia, which has acted to shift the country's pigmeat demand curve outward. Nevertheless, accounting for trade liberalization and its price effects is essential to clarify the change in the composition of pigmeat consumption by exporter origin.

\section{CONCLUSIONS}

In this paper, we analyze the impact of quarantine measures imposed by Australia on its imports of pigmeat accounting for the most important changes in policy since 1990, including the recent WTO dispute between Australia and EC. We econometrically estimate the tariff equivalent of four large changes in quarantine regimes for Australian pigmeat imports, 3 by major trade partner (Canada, Denmark, and USA) and a WTO dispute resolution. Using these estimates we then compute the impact of the regime changes on consumers, producers, and foreign exporters using a partial equilibrium model. The model is calibrated on the econometric estimates. The quarantine regimes have had a strong effect on trade and welfare and have a tariff equivalent above $113 \%$ expressed as a percent of average real border prices (averaged over the period 19982009 in 2005 prices). These effects are large because the tariff equivalents are large and the price 
responses of import demand are also relatively elastic (partly from the LES assumptions and the partly from small initial import volumes).

The Consumers' gains from removing the NTM tax equivalents are approximately AU\$409 million. The removal of the TBTs induces an increase in consumption of imported pigmeat of approximately $5.26 \mathrm{~kg}$ per person or 104.66 thousand metric tons (based on 2003 data to calibrate the effect). The estimated impact on the domestic pigmeat market is limited but with the caveat that the specification of the random utility model potentially constrains these effects.

Export revenues to Australia expand by AU\$245 million, AU\$109 million, and AU\$125 million for Canadian, Danish, and U.S. pigmeat respectively. From the evidence gathered in this study, early exporters benefited from subsequent trade liberalization intended to free other exporters' trade. The reforms created complementarity effects rather than competition effects. Canada benefited from the reforms of 1998 and 2004, and Denmark benefited from the 2004 reforms, which also enabled U.S. producers to export to Australia. This is contrary to what one might have expected given the potential trade diversion involved with a sequence of bilateral trade liberalizations. 


\section{REFERENCES}

Australian Government. ABARE. (2010). Email correspondence, September, 30.

Australian Government. ABARE. (2004). "Economic Assessment of the Effects of pigmeat imports on the Australian Industry, ABARE eReport 04.15 Prepared for the Market Access and Biosecurity Division, Australian Government Department of Agriculture, Fisheries and Forestry by Terry Sheales, Stephen Apted, and Dale Ashton, August.

Australian Government. Department of Agriculture, Fisheries and Forestry. (2004). "Generic Import Risk Analysis (IRA) for pigmeat" Final Import Risk Analysis Report, February.

Australian Government. Productivity Commission. (2008). "Safeguards Inquiry into the Import of Pigmeat" Productivity Commission Inquiry Report No. 44, 31 March.

Chaney, T, (2008). "Distorted Gravity: The Intensive and Extensive Margins of International Trade," The American Economic Review 98(4), 1707-21.

Heien, D.M., and C. R. Wessells. (1988). “The Demand for Dairy Products: Structure, Prediction, and Decomposition," American Journal of Agricultural Economics 70(2), 21928.

Helpman, E., M. Melitz, and Y. Rubinstein. (2008). "Estimating Trade Flows: Trading Partners and Trading Volumes," Quarterly Journal of Economics 123(2), 441-87.

Hummels, D., and A. Skiba. (2004). "Shipping the Good Apples Out? An Empirical Confirmation of the Alchian-Allen Conjecture." Journal of Political Economy 112(6):1384402.

James, S., and K. Anderson. (1998). "On the need for more economic assessment of quarantine policies," Australian Journal of Agricultural and Resource Economics 42(4), 425-44.

Peterson, E., and D. Orden. (2008). “Avocado Pests and Avocado Trade," American Journal of Agricultural Economics, Vol. 90, No. 2, 321-35. 
Phaneuf, D.J, C.L. Kling, and J. A. Herriges. (2000). "Estimation and Welfare Calculations in a Generalized Corner Solution Model with an Application to Recreation Demand," Review of Economics and Statistics 82:1, 83-92

Tanner, C. (1997). "Principles of Australian Quarantine” Australian Journal of Agricultural and Resource Economics 41(4), 541-58.

Tanner, C., and M. Nunn. (1998). “Australian quarantine post the Nairn Review,” Australian Journal of Agricultural and Resource Economics 42(4), 445-58.

WTO. (2007). Australia - Quarantine regime for imports. Notification of Mutually Agreed Solution, Document WT/DS287/8 G/L/618/Add.1 G/SPS/GEN/384/Add.1, 13 March 2007.

World Trade Organization. 2003. Australia - Quarantine regime for imports. Request for consultation. Document WT/DS287/1G/L/618, G/SPS/GEN/384, 9 April.

Wales, T.J., and A.D. Woodland. (1983). "Estimation of Consumer Demand Systems with Binding Nonnegativity Constraints.” Journal of Econometrics 21, 263-85.

Yue, C., and J. Beghin. (2009). “The Tariff Equivalent and Forgone Trade Effects of Prohibitive Technical Barriers to Trade," American Journal of Agricultural Economics 91(4), 930-41. Yue, C., and J.C. Beghin. (2009b). “AJAE Appendix: The Tariff Equivalent and Forgone Trade Effects of Prohibitive Technical Barriers to Trade." Available on AgEcon Search.

Yue, C., J.C. Beghin, and H.H. Jensen. (2006). "Tariff Equivalent of Technical Barriers to Trade with Imperfect Substitution and Trade Costs." American Journal of Agricultural Economics 88(4), 947-60. 


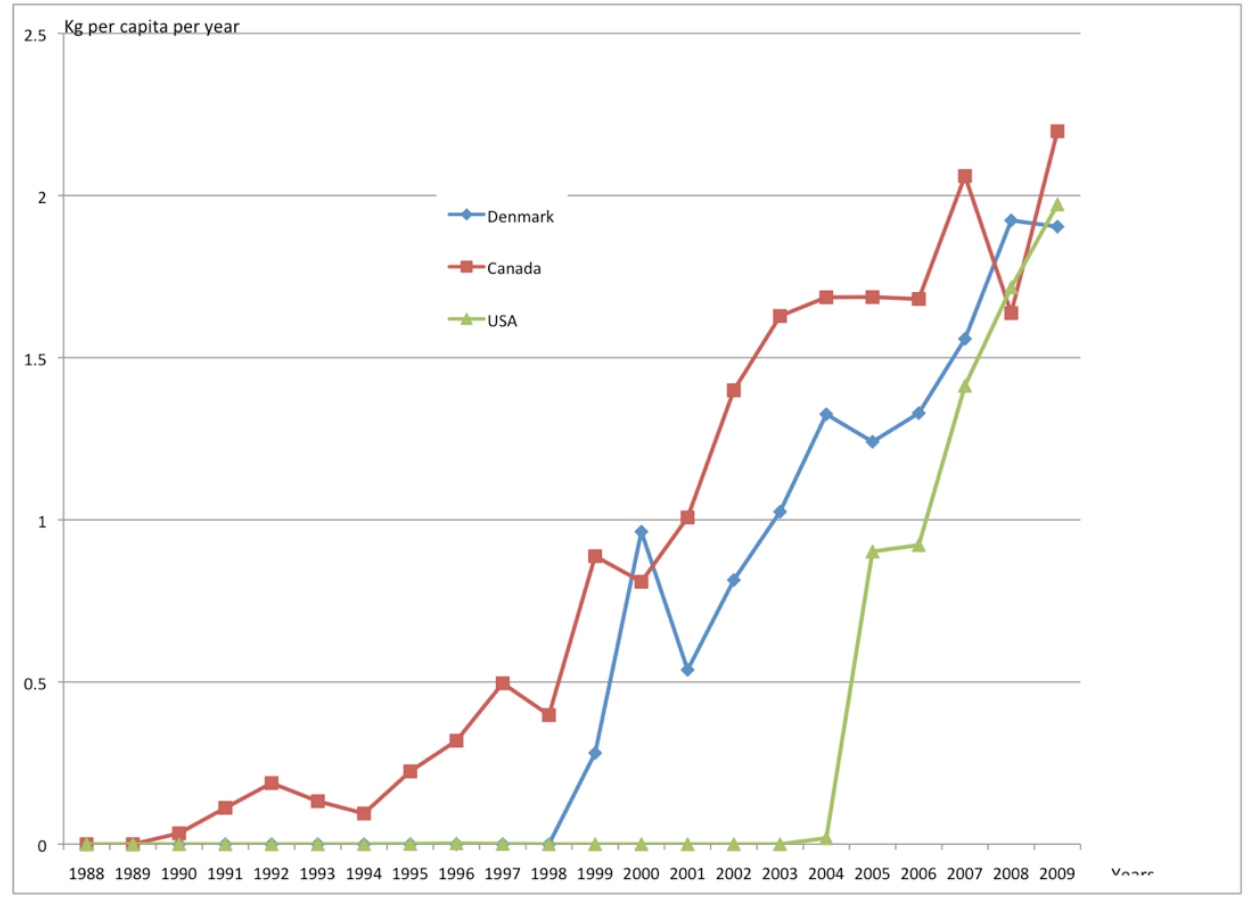

Figure 1. Imported pigmeat consumption per capita

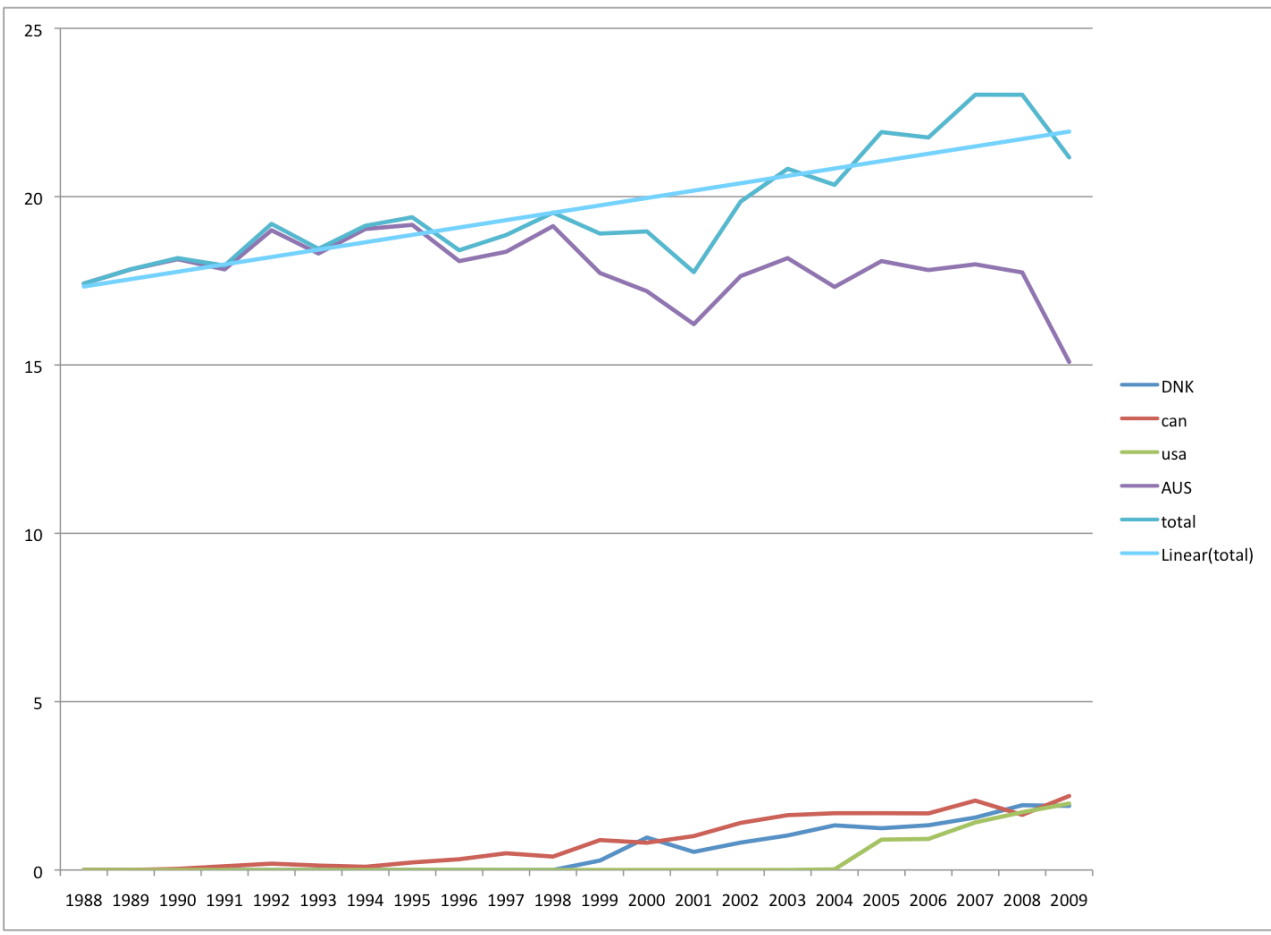

Figure 2. Total pigmeat consumption per capita and sourcing composition (kg/year) 
Table 1. Econometric estimation of demand parameters ${ }^{1}$

\begin{tabular}{|c|c|c|c|c|c|}
\hline $\begin{array}{l}\text { Instantane } \\
\text { parameter }\end{array}$ & $\begin{array}{l}\text { is implemen } \\
\text { estimate }\end{array}$ & $\begin{array}{l}\text { ation (no lag i } \\
\text { std deviation }\end{array}$ & $\begin{array}{l}\text { implementatio } \\
\text { approximate } t\end{array}$ & $\%$ TBT & average real wp \\
\hline$\delta_{\text {aust }}$ & 1 & na & na & & \\
\hline$\delta_{d n k}$ & 1.8887 & 0.5586 & 3.381 & & \\
\hline$\delta_{c a n}$ & 2.8242 & 0.4910 & 5.752 & & \\
\hline$\delta_{u s a}$ & 1.8679 & 0.5306 & 3.521 & & \\
\hline$\delta_{a o g}$ & 9259.5370 & 1186.9110 & 7.801 & & \\
\hline$\omega_{\text {aust }}$ & -17.3628 & 0.0755 & -230.119 & & \\
\hline$\omega_{i m p}$ & 0.6665 & 0.1503 & 4.435 & & \\
\hline$N T M_{d n k}$ & 7.0412 & 3.0616 & 2.300 & $133 \%$ & AU\$5.30 \\
\hline$N T M_{c a n}$ & 9.7636 & 3.3681 & 2.899 & $199 \%$ & AU\$4.90 \\
\hline$N T M_{\text {usa }}$ & 11.0811 & 4.8394 & 2.290 & $186 \%$ & AU\$5.97 \\
\hline
\end{tabular}

6-month lagged implementation

parameter estimate std deviation approximate t \% TBT average real wp

\begin{tabular}{lrrccc}
$\delta_{\text {aust }}$ & 1 & na & na & & \\
$\delta_{\text {dnk }}$ & 1.7288 & 0.5598 & 3.0881 & & \\
$\delta_{\text {can }}$ & 2.6945 & 0.4788 & 5.6279 & & \\
$\delta_{\text {usa }}$ & 1.9207 & 0.5228 & 3.6736 & & \\
$\delta_{\text {aog }}$ & 9383.1170 & 1181.0340 & 7.9448 & & \\
$\omega_{\text {aust }}$ & -17.3573 & 0.0778 & -223.1027 & & \\
$\omega_{\text {imp }}$ & 0.5418 & 0.1346 & 4.0246 & & \\
$N T M_{\text {dnk }}$ & 8.6932 & 3.5784 & 2.4294 & $164 \%$ & AU $\$ 5.30$ \\
$N T M_{\text {can }}$ & 12.2736 & 4.0601 & 3.0230 & $250 \%$ & AU $\$ 4.90$ \\
$N T M_{\text {usa }}$ & 16.4574 & 7.2373 & 2.2740 & $276 \%$ & AU $\$ 5.97$ \\
\hline
\end{tabular}

12-month lagged implementation

parameter estimate std deviation approximate $t$ \% TBT average real wp

$\begin{array}{lrrcrl}\delta_{\text {aust }} & 1 & \text { na } & \text { na } & & \\ \delta_{\text {dnk }} & 1.833229 & 0.57046346 & 3.214 & & \\ \delta_{\text {can }} & 2.834021 & 0.4974053 & 5.698 & & \\ \delta_{\text {usa }} & 1.989005 & 0.54997553 & 3.617 & & \\ \delta_{\text {aog }} & 9354.47 & 1179.525 & 7.931 & & \\ \omega_{\text {aust }} & -17.36314 & 0.07631379 & -227.523 & & \\ \omega_{\text {imp }} & 0.684078 & 0.15574446 & 4.392 & & \\ N T M_{\text {dnk }} & 5.963411 & 2.73731213 & 2.179 & 113 \% & \text { AU\$5.30 } \\ N T M_{\text {can }} & 8.859753 & 3.12424523 & 2.836 & 181 \% & \text { AU\$ } \$ 4.90 \\ N T M_{\text {usa }} & 11.14436 & 4.83059164 & 2.307 & 187 \% & \text { AU\$5.97 }\end{array}$

${ }^{1}$ mean and std for $\delta_{\text {aog }}$ are computed by generating 500 draws of $\omega_{\text {aus }}$ and computing 500 estimates of $\delta_{\text {aog }}$ evaluated at the mean of other variables appearing in constraint (14) and finally computing their mean and std. 
Table 2. Estimated welfare and trade effects ${ }^{1}$

\section{CV per capita (AU\$)}

Total CV (AU\$)

Producer surplus change (AU\$)

Total welfare

Canadian imports (mt)

Danish imports (mt)

U.S. imports (mt)

Canadian imports (AU\$)

Danish imports (AU\$)

U.S. imports (AU\$))

\section{$\$ 20.57$}

$\$ 409,157,146$

$\$(102,036)$

$\$ 409,055,110$

$51,345.74$

$25,134.50$

$28,184.98$

$\$ 244,886,641$

$\$ 108,694,338$

$\$ 124,814,181$

${ }^{1}$ Calibrated on 2003 initial levels of population and Australian pigmeat quantities and prices 